\title{
ВИКОРИСТАННЯ ПРИНЦИПІВ МЕДИЧНОЇ ОНТОЛОГІЇ ДЛЯ ПОБУДОВИ СЦЕНАРНИХ МОДЕЛЕЙ ПІСЛЯДИПЛОМНОГО НАВЧАННЯ ЛІКАРІВ І ПРОВI3OPIB
}

\author{
О. П. Мінцер, О. Є. Стрижак', С. В. Денисенко \\ Національна медична академія післядипломної освіти імені П. Л. Шупика \\ Національний центр «Мала академія наук України»"
}

\begin{abstract}
Описуються підходи, засоби та технології формування персоніфікованих електронних майданчиків управління знаннями в навчально-інформаційному середовищі. Розглянуті онтологічні аспекти побудови моделі е-сценарію супроводу процесу навчання/перепідготовки лікаря з використанням мережевих систем знань. Це припускає вирішення актуальних проблем підвищення ефективності навчання лікарів на основі застосування сучасних мережевих технологій дистанційного доступу до розподілених систем знань.
\end{abstract}

Ключові слова: онтологія медичних знань, персоніфікований електронний майданчик, інформаційні джерела формування знань, онтологічна модель е-сценарію процесу супроводу навчального процесу.

\section{ИСПОЛЬЗОВАНИЕ ПРИНЦИПОВ МЕДИЦИНСКОЙ ОНТОЛОГИИ ДЛЯ ПОСТРОЕНИЯ СЦЕНАРНЫХ МОДЕЛЕЙ ПОСЛЕДИПЛОМНОГО ОБУЧЕНИЯ ВРАЧЕЙ И ПРОВИЗОРОВ}

\author{
О. П. Минцер, А. Е. Стрижак', С. В. Денисенко \\ Национальная медицинская академия последипломного образования \\ имени П. Л. Шупика \\ Национальный центр «Малая академия наук Украины» ${ }^{1}$
}

\begin{abstract}
Описываются подходы, средства и технологии формирования персонифицированных электронных площадок управления знаниями в учебно-информационной среде. Рассмотрены онтологические аспекты построения модели е-сценария сопровождения процесса обучения/переподготовки врача с использованием сетевых систем знаний. Это предполагает решение актуальных проблем повышения эффективности обучения врачей на основе применения современных сетевых технологий дистанционного доступа к распределенным системам знаний.
\end{abstract}

Ключевые слова: онтология, онтология медицинских знаний, персонифицированная электронная площадка, информационные источники формирования знаний, онтологическая модель е-сценария процесса сопровождения учебного процесса.

\section{USE OF PRINCIPLES OF MEDICAL ONTOLOGY FOR CONSTRUCTION OF SCENARIO MODELS OF POST-GRADUATE EDUCATION OF DOCTORS AND PHARMACISTS}

\author{
O. P. Mintser, O. Ye. Stryzhak', S. V. Denysenko \\ National Medical Academy of Post-Graduate Education by P. L. Shupyk \\ National center Minor Academy of Sciences of Ukraine ${ }^{1}$
}

\begin{abstract}
Approaches, facilities and technologies of forming of the personalized electronic grounds of management in the educationalinformative environment knowledge are described. The ontological aspects of model scenario construction in doctor's education post-graduate training accompaniment are considered with the use of the network systems of knowledge. It supposes the decision of increasing of efficiency medical educating of doctors on application of modern network technologies of the distance access to the distributed knowledge systems.
\end{abstract}

Key words: ontology, ontology of medical knowledge, personalized electronic basis, informative sources of knowledge forming and ontological model of e-scenario of process of educational process accompaniment.

О О. П. Мінцер, О. Є. Стрижак, С. В. Денисенко 
Вступ. Сучасні досягнення комп'ютерних наук у сфері освіти привели до спільного використання даних у багатьох різних сховищах. Використання інформаційно-комунікаційних технологій (IКТ) сумовою забезпечення новаторської альтернативи традиційному навчанню, створюючи можливості для персонального навчання, інтерактивного заняття та колективної роботи в комп'ютерній мережі незалежно від місця розташування слухача. Світ стає цифровим і ефективне використання цифрових технологій у різних галузях економіки, включаючи освіту, науку та бізнес, стає непорушною умовою існування. Очевидно, що ключовим моментом стає доступ до інформаційних джерел формування знань, що розміщуються у відповідних середовищах і доступних із будьякого місця та у будь-який час [10].

При розробці корпоративних систем управління інформаційними джерелами в завданнях витягання, трансферу та використання знань основною проблемою є забезпечення цілеспрямованого пошуку, формулювання, формування, структуризації та представлення даних і повідомлень, із яких надалі формуються знання. Корпоративна інформаційно-юмунікаційна система (IКС) в сучасному світогляді є складовою освітніх організаційних структур (ООС). Саме вона забезпечує ефективну реалізацію корпоративних IКТ - процесів, в якій збір і оброблення даних здійснюється автоматизовано за допомогою відповідних засобів комп'ютерної техніки та IКТ. Засоби та технології корпоративної ІКС утворюють в ООС адаптивне, інтегроване інформаційно-освітнє середовище, що розвивається й активно здійснює визначальний вплив на формування в ООС найбільш сприятливих (інформаційно-комфортних) умов для ефективного здійснення його функцій [ 1 ]. При цьому зростають вимоги до підвищення продуктивності IКТ. їх надійності при постійному збільшенні обсягів оброблених даних.

Мета роботи - представлення онтологічних аспектів побудови моделі е-сценарію супроводу процесу навчання/перепідготовки лікаря з використанням мережевих систем знань.

Результати та їх обговорення. Використання програмно-інформаційних засобів ІКТ в освітньому просторі Національної медичної академії післядипломної освіти імені П. Л. Шупика забезпечує побудову персоніфікованого корпоративного комп'ютерно-інтегрованого навчального середовища, в якому підтримуються режими безперервної електронної дистанційної взаємодії між лікарями-практиками та викладачами різних кафедр, і зокрема супроводи курсу лікування. Дистанційне навчання є різновидом на- вчання, при якому учасники й організатори навчального процесу здійснюють переважно індивідуалізовані взаємодії як асихронно, так і синхронно в часі, використовуючи електронні транспортні системи постачання навчальних матеріалів і інших інформаційних об'єктів, комп'ютерні мережі Інтернет/Інтранет, IKT [3]. Одним із завдань діяльності в цьому середовищі є надання умов ефективного використання інформаційних ресурсів усіма учасниками навчального процесу в медичній установі для освоєння лікарями нових знань в галузі діагностики та лікування захворювань. Для цього створюються засоби формалізації навчальних інформаційних джерел формування знань, що враховують специфіку лікувального процесу.

За допомогою програмно-інформаційних компонентів IКТ забезпечується створення та використання баз навчальних і наукових джерел, на основі яких реалізується освітній процес для конкретної особи. При застосуванні програмно-інформаційних засобів IКТ у лікувальній практиці лікаря повинен враховуватися той факт, що обсяг і різноманітність даних і повідомлень із різних профілів медичних знань нині настільки величезні, що виникає необхідність їх класифікації 3 точки зору належності до конкретної предметної області. Йдеться не лише про дані, що зберігаються в спеціалізованих базах або інформаційних сховищах, але й про динамічні повідомлення, генеровані певними джерелами при необхідності.

Застосування програмно-інформаційних засобів IKT орієнтоване на вирішення таких завдань:

- забезпечення можливості оперативної організації доступу до інформаційних джерел формування знань, що стосуються однієї предметної області або об'єднаних схожими інтересами сфер діяльності;

- підтримка взаємодії всіх учасників навчального процесу в рамках неодиничної безлічі предметних областей із можливістю розширення цієї великої кількості;

- забезпечення можливості розширення списку джерел і споживачів різнорідних інформаційних джерел формування знань у рамках певної предметної області або сфери інтересів;

- обмеження доступу до інформаційних ресурсів навчального призначення рамками конкретної предметної області або сфери інтересів у зв'язку з можливістю вирішення попереднього завдання;

- забезпечення кожному суб'єкту освітнього процесу можливості використання інформаційних ресурсів навчального призначення декількох предметних областей; 
- забезпечення можливості оперативного пошуку слухачами джерела необхідних інформаційних ресурсів стосовно конкретної предметної області [7].

Основою формування корпоративного персоніфікованого комп'ютерно-інтегрованого навчального середовища є накопичення не розрізнених даних, а структуровані, формалізовані закономірності та принципи, що дозволяють вирішувати реальні завдання при виконанні освітньої діяльності слухачами. Онтологічний підхід до проектування персоніфікованих корпоративних IКС якраз і дозволяє створювати системи, в яких інформаційні джерела формування знань стають доступними для всіх учасників навчального процесу. Можна виділити такі основні переваги подібного підходу:

- онтологічний підхід надає користувачеві цілісний, системний погляд на певну предметну область;

- інформаційні джерела про предметну область представлені однотипно, що спрощує їх сприйняття;

- побудова онтології дозволяє відновити бракуючі логічні зв'язки предметної області.

Важливість онтологічного підходу в створенні персоніфікованих корпоративних ІКС навчального призначення обумовлена також тим, що, якщо інформаційні джерела формування знань не описати та не тиражувати, вони, в підсумку, застарівають і стають неактуальними. Інформаційні ж джерела формування знань, що поширюються та використовуються, можуть бути використані для генерування нового знання.

Онтологічний підхід дозволяє подавати терміни, поняття у такому вигляді, що вони стають придатними для комп'ютерного оброблення. Він об'єднує круг питань, починаючи від сфери застосування, формального опису компонентів предметних областей. На формальному рівні, онтологія - система, що складається з безлічі термінів, тверджень про ці поняття, на основі яких можна будувати класи, об 'єкти, зв' язки, функції і теорії. Комп'ютерну онтологію деякої предметної дисципліни можна розглядати як загальнозначущу, відкриту базу інформаційних джерел формування знань, представлену загальноприйнятою (формальною) мовою специфікації. У онтолого-класифікаційній схемі засобів і методів штучного інтелекту онтологічний підхід трактується як різновид системного підходу, грунтованого на формуванні знань. Онтологічний підхід забезпечує ефективне проектування компонентів будь-якої знання-орієнтованої інформаційної системи $[5,11,12]$.

Практично всі моделі онтології містять певні концепти (поняття, класи), властивості концептів (атри- бути, ролі), стосунки між концептами (залежності, функції) та додаткові обмеження, що визначаються аксіомами. Концептом може бути опис завдання, функції, дії, стратегії, процесу міркування, хід здійснення дослідження і так далі [4]. При цьому увага спрямована на формалізацію етапів побудови, структуризації та представлення інформаційних джерел формування знань дозволяє слухачам ефективніше засвоювати лекційний матеріал у поєднанні з практичними завданнями. В свою чергу, ефективна реалізація вказаних етапів і отримання кінцевого результату (бібліотеки онтологічних баз інформаційних джерел формування знань) неможлива без проведення системно-онтологічного аналізу заданої сукупності інформаційних навчальних ресурсів [6].

Поняття онтології й онтологічного аналізу увійшли до процедур і стандартів моделювання корпоративних IКС навчального призначення. Адже описом таких систем є структуризація інформаційних джерел формування знань. Реалізація вказаних технологій вимагає обліку різних формально-методологічних вимог, критеріїв і оцінок. Основні з них:

1. Побудова інформаційної і функціональної моделей.

2. Необхідність структуризації термінів і понять.

3. Правила формування достовірних тверджень i висновків, що описують терміни та поняття [6].

На початковому етапі побудови онтологічної моделі мають бути виконані такі завдання:

- створення та документування словника термінів;

- опис правил, згідно з якими на базі введеної термінології формуються достовірні твердження, що характеризують стан системи;

- побудова моделі, за допомогою якої на основі існуючих тверджень можна формувати необхідні додаткові твердження [4]. Онтологічна система характеризується єдністю, логічним взаємозв'язком і несуперечністю використовуваних понять.

Візуальні методи проектування онтологій сприяють швидкому та повному розумінню структури знань предметної області [9], що особливо цінно для лікарів, які освоюють нові методики лікування. При виконанні персональних навчальних програм перед слухачем виникає необхідність оперативного спілкування з викладачами. При цьому об'єктивні обставини - час i місце спілкування, не завжди співпадають із можливостями слухача та викладача. Також навчальна програма, яку виконує слухач, не завжди повною мірою відображає процес проведення курсу лікування, консультаційної взаємодії й оцінку результатів, а містить тільки загальні методичні рекомендації з іiі 
виконання. Тому виникає необхідність створення системи електронної дистанційної підтримки виконання прийняття рішень лікарями при обгрунтуванні курсу лікування за певною методикою. Одним із підходів, що забезпечить ефективне функціонування такої системи, є побудова онтологічної моделі е-сценарію супроводу процесу лікування. Він є системою формалізації лікувальних процедур за допомогою онтологічного підходу їі побудови, операційно, покроково відтворюючи маршрут лікування. При цьому передбачається використання інформаційної підтримки лікаря шляхом об 'єднання різних засобів Інтернет - технологій і програмних модулів (мережеві електронні наукові та навчально-методичні ресурси, бази даних, сервісно-функціональні й аналітичні програмні модулі тощо), котрі формуються з певної галузі знань і безлічі цілей лікувального курсу. Ці ресурси не лише істотно урізноманітнюють змістовну складову еметодичних систем підтримки медичної діяльності, але й ураховують специфіку реалізації всього процесу навчання [2].

Процес формування онтологічної моделі е-сценарію супроводу процесу курсу лікування полягає в тому, що маючи опис певних понять, можна погоджено представляти їх у вигляді об'єктів засобами побудови онтології [9]. Для візуалізації створення онтологічних моделей нами використана комп'ютерна програма "Трафсдитор". Початковими даними для неї служили описи об'єктів, представлені безліччю їх ознак. Початкові дані можуть бути представлені у вигляді текстового файлу. Структура текстового файлу в цьому випадку така:

Таблиця 1. Загальна формалізована структура онто
(Ім'я об'єкту 1)... (ім'я ознаки п),

(Ім'я об'єкту 2)... (ім'я ознаки ј)

(Ім'я об'єкту m) ... (ім'я ознаки к).

Онтологічна модель супроводу процесу курсу лікування (е-сценарій) була створена за допомогою вказаного комп'ютерного засобу.

Загальна формула формалізації цієї онтологічної моделі: $\mathrm{S}=\{\mathrm{Oa}\{\mathrm{Pb}\{\mathrm{Td}\{\mathrm{Ee}\{\mathrm{Cq}\{\mathrm{Mv}\{\mathrm{Zg}\} \mathrm{Rh}$ $\{\mathrm{Zg}\}\}\}\}\}\}\}$, де

- суб'єкти лікувального курсу: $\mathrm{B}=\{\mathrm{Oa}\}, \mathrm{a}=1,2,3$, ... т ;

- кластери лікувального курсу: $\mathrm{P}=\{\mathrm{Oa}\{\mathrm{Pb}\}\} \mathrm{b}=$ a1, a2, a3,.., An;

- система діагнозів лікувального курсу: $\mathrm{T}=\{\mathrm{Pb}$ $\{\mathrm{Td}\}\} \mathrm{d}=\mathrm{b} 1, \mathrm{~b} 2, \mathrm{~b} 3, \ldots, \mathrm{Bn}$;

- етапи лікувального курсу: $\mathrm{E}=\{\mathrm{Td}\{\mathrm{Ee}\}\}$ e $=\mathrm{dl}$, $\mathrm{d} 2, \mathrm{~d} 3, \ldots$, Dn;

- мета лікувального курсу: $\mathrm{C}=\{\mathrm{Ee}\{\mathrm{Cq}\}\} \mathrm{q}=\mathrm{el}$, e2, e3,..., En;

- засоби лікувального курсу: $Z=\{\mathrm{Cq}\{\mathrm{Zg}\}\} \mathrm{g}=\mathrm{q} 1$, $\mathrm{q} 2, \mathrm{q} 3, \ldots, \mathrm{Qn}$;

- маршрут лікувального курсу: $\mathrm{M}=\{\mathrm{Cq}\{\mathrm{Mv}$ $\{\mathrm{Zg}\}\}\}, \mathrm{v}=\mathrm{g} 1, \mathrm{~g} 2, \mathrm{~g} 3, \ldots, \mathrm{Gn} ; "$

- оцінювання результатів: $\mathrm{R}=\{\mathrm{Cq}\{\mathrm{Rh}\{\mathrm{Zg}\}\}\} \mathrm{h}=$ v1, v2, v3,.., Hn.

Формалізована структура онтологічної моделі е-сценарію супроводу курсу лікування певного захворювання представлена в таблиці 1 , а на рисунку 1 зображена загальна графорієнтована структура онтологічної моделі е-сценарію супроводу навчального процесу 3 вивчення нової методики лікування лікарями.

ічної моделі е-сценарію супроводу курсу лікування

\begin{tabular}{|c|c|c|c|}
\hline Найменування & $\begin{array}{l}\text { Назва } \\
\text { класу }\end{array}$ & Назва ознаки & $\begin{array}{l}\text { Умови ідентифікації } \\
\left.\text { ознаки: }\{\mathrm{x} \mid \mathrm{F}(\mathrm{x})\}^{*}\right)\end{array}$ \\
\hline Суб'єкти лікувального курсу & $\mathrm{O}$ & $\left\{\mathrm{O}_{\mathrm{a}}\right\}$ & $\left\{\mathrm{O}_{\mathrm{a}} \mid \mathrm{F}\left(\mathrm{O}_{\mathrm{a}}\right)\right\}$ \\
\hline$\left\{\mathrm{O}_{\mathrm{a}}\right\}$ & $\mathrm{P}$ & $\begin{array}{l}\text { Системи організму } \\
\text { лікувального курсу }\end{array}$ & \\
\hline Кластери лікувального курсу & $\mathrm{P}$ & $\left\{\mathrm{O}_{\mathrm{a}}\left\{\mathrm{P}_{\mathrm{b}}\right\}\right\}$ & $\left\{\mathrm{O}_{\mathrm{a}}\left\{\mathrm{P}_{\mathrm{b}}\right\} \mid \mathrm{F}\left(\mathrm{O}_{\mathrm{a}}\left\{\mathrm{P}_{\mathrm{b}}\right\}\right)\right\}$ \\
\hline$\left\{\mathrm{O}_{\mathrm{a}}\left\{\mathrm{P}_{\mathrm{b}}\right\}\right\}$ & $\mathrm{T}$ & Діагнози лікувального курсу & \\
\hline Система діагнозів лікувального курсу & $\mathrm{T}$ & $\left\{\mathrm{P}_{\mathrm{b}}\left\{\mathrm{T}_{\mathrm{d}}\right\}\right\}$ & $\left\{\mathrm{P}_{\mathrm{b}}\left\{\mathrm{T}_{\mathrm{d}}\right\} \mid \mathrm{F}\left(\mathrm{P}_{\mathrm{b}}\left\{\mathrm{T}_{\mathrm{d}}\right\}\right)\right\}$ \\
\hline$\left\{\mathrm{P}_{\mathrm{b}}\left\{\mathrm{T}_{\mathrm{d}}\right\}\right\}$ & $\mathrm{E}$ & Етапи лікувального курсу & \\
\hline Етапи лікувального курсу & $\mathrm{E}$ & $\left\{\mathrm{T}_{\mathrm{d}}\left\{\mathrm{E}_{\mathrm{e}}\right\}\right\}$ & $\left\{\mathrm{T}_{\mathrm{d}}\left\{\mathrm{E}_{\mathrm{e}}\right\} \mid \mathrm{F}\left(\mathrm{T}_{\mathrm{d}}\left\{\mathrm{E}_{\mathrm{e}}\right\}\right)\right\}$ \\
\hline$\left\{\mathrm{T}_{\mathrm{d}}\left\{\mathrm{E}_{\mathrm{e}}\right\}\right\}$ & $\mathrm{C}$ & Мета лікувального курсу & \\
\hline Мета лікувального курсу & $\mathrm{C}$ & $\left\{\mathrm{E}_{\mathrm{e}}\left\{\mathrm{C}_{\mathrm{a}}\right\}\right\}$ & $\left\{\mathrm{E}_{\mathrm{e}}\left\{\mathrm{C}_{\mathrm{a}}\right\} \mid \mathrm{F}\left(\mathrm{E}_{\mathrm{e}}\left\{\mathrm{C}_{\mathrm{a}}\right\}\right)\right\}$ \\
\hline$\left\{\mathrm{E}_{\mathrm{e}}\left\{\mathrm{C}_{\mathrm{a}}\right\}\right\}$ & $\mathrm{R}$ & Засоби лікувального курсу & \\
\hline Засоби лікувального курсу & $\mathrm{R}$ & $\left\{\mathrm{C}_{0}\left\{\mathrm{R}_{\mathrm{g}}\right\}\right\}$ & $\left\{\mathrm{C}_{\mathrm{a}}\left\{\mathrm{R}_{\mathrm{g}}\right\} \mid \mathrm{F}\left(\mathrm{C}_{\mathrm{a}}\left\{\mathrm{R}_{\mathrm{g}}\right\}\right)\right\}$ \\
\hline$\left\{\mathrm{T}_{\mathrm{d}}\left\{\mathrm{E}_{\mathrm{e}}\right\}\right\}$ & $\mathrm{M}$ & Маршрут лікувального курсу & \\
\hline Маршрут лікувального курсу & $\mathrm{M}$ & $\left\{\mathrm{C}_{\mathrm{a}}\left\{\mathrm{M}_{\mathrm{v}}\left\{\mathrm{R}_{\mathrm{q}}\right\}\right\}\right\}$ & $\left\{\mathrm{C}_{\mathrm{a}}\left\{\mathrm{M}_{\mathrm{v}}\left\{\mathrm{R}_{\mathrm{q}}\right\}\right\} \mid \mathrm{F}\left(\mathrm{C}_{\mathrm{o}}\left\{\mathrm{M}_{\mathrm{v}}\left\{\mathrm{R}_{\mathrm{q}}\right\}\right\}\right)\right\}$ \\
\hline$\left\{\mathrm{C}_{\mathrm{a}}\left\{\mathrm{M}_{\mathrm{v}}\left\{\mathrm{R}_{\mathrm{g}}\right\}\right\}\right\}$ & $\mathrm{O}$ & Оцінювання результатів & \\
\hline Оцінювання результатів & $\mathrm{O}$ & $\left\{\mathrm{C}_{\mathrm{a}}\left\{\mathrm{O}_{\mathrm{h}}\left\{\mathrm{R}_{\mathrm{g}}\right\}\right\}\right\}$ & $\left\{\mathrm{C}_{\mathrm{a}}\left\{\mathrm{O}_{\mathrm{h}}\left\{\mathrm{R}_{\mathrm{g}}\right\}\right\} \mid \mathrm{F}\left(\mathrm{C}_{\mathrm{a}}\left\{\mathrm{O}_{\mathrm{h}}\left\{\mathrm{R}_{\mathrm{g}}\right\}\right\}\right)\right\}$ \\
\hline
\end{tabular}

*) Умови ідентифікації ознаки: $\{\mathrm{x} \mid \mathrm{F}(\mathrm{x})\}$ - визначає множину всіх х таких, що вірно $\mathrm{F}(\mathrm{x})$. Приклад: $\{\mathrm{kKa} \mid \mathrm{k}<5]=\{1,2,3,4\}$. 


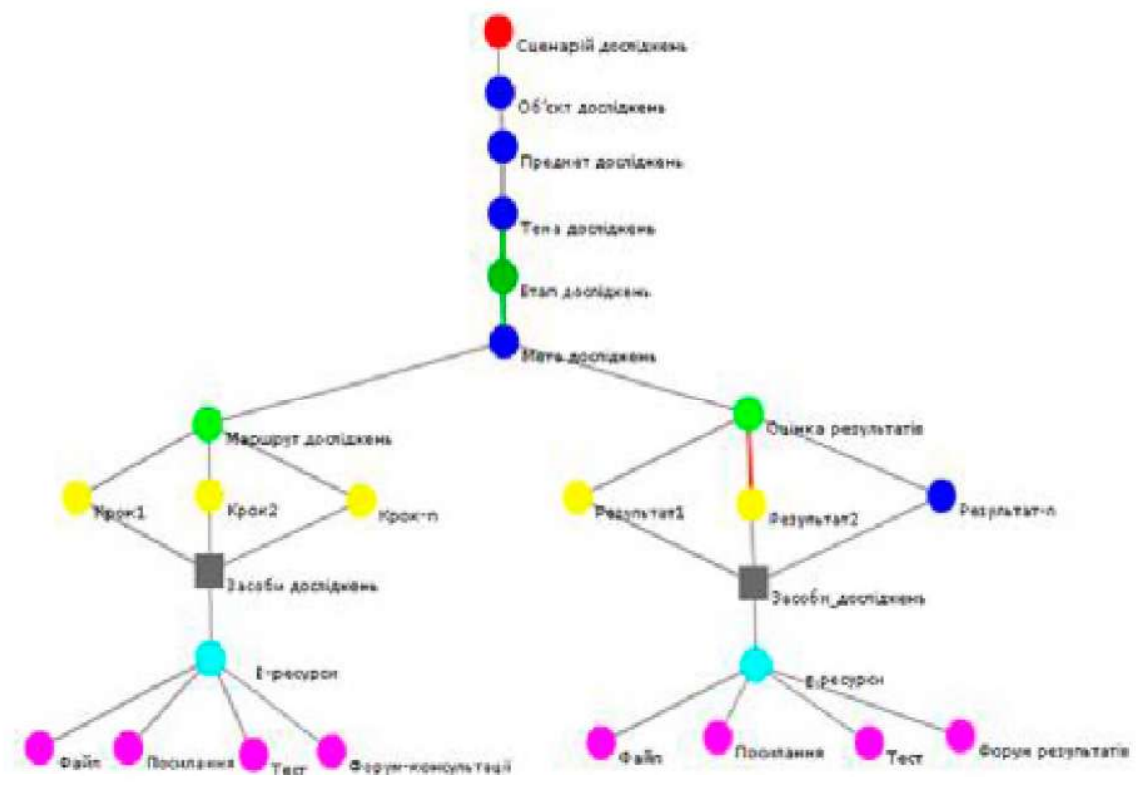

Puc. 1. Загальна графорієнтована структура онтологічної моделі е-сценарію супроводу навчального процесу з вивчення нової методики лікування лікарями.

Висновки. Одним із перспективних напрямів для подальшого вдосконалення освітніх організаційних структур у медицині є розроблення методологічних, онтологічних і логічних основ конструювання баз інформаційних джерел формування знань. Онтології грають вирішальну роль у моделі опису формування таких систем. Це припускає рішення актуальних проблем підвищення ефективності безперервного професійного розвитку лікарів і провізорів на основі застосування сучасних мережевих технологій дистанційного доступу до розподілених систем формування

\section{Література}

1. Биков В. Ю. Технології хмарних обчислень, ІКТ-аутсорсінг та нові функції ІКТ-підрозділів навчальних закладів і наукових установ [Електроннийресурс] /В.Ю.Биков//Інформаційно-юмунікаційні технології в освіті: зб. наук, праць. -Херсон: ХДУ 2011. -Вип. 10. - Режим доступу : http:// ite.ksu.ks.ua/2011/випуск-10.

2. Биков В. Ю. Електронна педагогіка та сучасні інструменти систем відкритої освіти [Електронний ресурс] / В. Ю. Биюв, І. В. Мушка// Інформаційні технології і засоби навчання. - 2009 . - №5(13). - Режим доступу до журналу : http://www.ime.edu-ua.net/em.html.

3. Биков В. Ю. Моделі організаційних систем відкритої освіти: монографія/В.Ю.Биков,-К.: Атіка,2008.-684c. :іл. 4. Гладун А. Я. Онтологии в корпоративных сетях [Электронный ресурс] / А. Я. Гладун, Ю. В. Рогушина // Корпоративные информационные системы. - 2006. - № 1. - Режим доступу: littp://www.mamgement.com.ua/ims/ims 115 .html. 5. Гладун В. П. Процессы формирования новых знаний / знань. Природним при цьому є створення онтологічних описів і моделювання подій, що визначають курс діагностики і лікування захворювань.

Використання запропонованого методу побудови онтологічної моделі е-сценарію супроводу лікувального процесу дозволяє зробити цей процес більш персоніфікованим. Іншими словами, підвищення якості передавання знань досягається за рахунок того, що лікар має можливість використати свій власний досвід, будувати свої моделі формування та використання знань.

В. П. Гладун. - София: Педагог 6,1994.-192 с.

6. Дем'яненко В. Б. Комп'ютерні онтології-технологічна основа формування освітянських інформаційних ресурсів [Електронний ресурс] /В. Б. Дем'яненко, О. Є. Стрижак// Інформаційні технології і засоби навчання. - 2011. - Том 22. - № 2. - Режим доступу: http://journal.iitta.gov.ua/ index.php/itlt/article/view/419.

7. Стрижак О. Є. Інформаційно-технологічні рішення формування операційного простору діяльності обдарованої особистості [Електронний ресурс] / [Г. Востров, С. Кальной, О. Павлов та ін.]. - Режим доступу: http:// archive.nbuv.gov.ua/portaVSoc_Gum/Nivoo/2010_4/22.pdf. 8. Мананникова Н. Н. Учебно-исследовательская работа учащихся: методические рекомендации для учащихся и педагогов [Электронный ресурс] / Н. Н. Мананникова. Режим доступу: http://nsportal.ru/blog/shkola/ obshcheshkolnaya-tematika/nauchno-issledovatelskayarabota-uchashchikhsya. 
9. Применение методов и средств онтологического анализа для управления образовательной деятельностью / В. В. Мартынов, В. И. Рыков, Е. И. Филосова, Ю. В. Шаронова // Вестник УГАТУ Управление в социальных и экономических системах.-Уфа: УГАТУ 2012.-Т. 16.-№3 (48). - C. 230-234.

10. Морзе Н. В. Інформатичні компетентності професора - міф чи реальність? [Електронний ресурс] / Н. В. Морзе // Електронний депозитарій. Національний педагогічний університет імені М. П. Драгоманова. - Вип. 9. - Режим доступу: http://enpuir.npu.edu.ua/handle/123456789/691/ browse type $=$ author $\&$ order $=\mathrm{ASC} \& \mathrm{rpp}=20 \&$ value $=$
$\% \mathrm{D} 0 \% 9 \mathrm{C} \% \mathrm{D} 0 \% \mathrm{BE} \% \mathrm{D} 1 \% 80 \% \mathrm{D} 0 \% \mathrm{~B} 7 \% \mathrm{D} 0 \% \mathrm{~B} 5 \% 2 \mathrm{C}+\%$ D0\%9D\%D0\%92.

11. Палагин А. В. К проектированию онтологоуправляемой информационной системы с обработкой естественно-языковых объектов / А. В. Палагин, Н. Г. Петренко // Математические машины и системы. - 2008. -№ 2. - С. 14-23.

12. СтрижакО. Є. Комп'ютерні тезауруси як технологічна платформа створення авторських методик викладання предметних дисциплін/О. С. Стрижак//Актуальні проблеми психології: Психологічна теорія і технологія навчання / за ред. С. М Максименко, М. ЈI Смульсон. - К.: НПУ імені М. П. Драгоманова 2009. - Т. 8. - Вип. 6. - С. 259-266. 